\title{
CAIX Inhibitor DTP348
}

National Cancer Institute

\section{Source}

National Cancer Institute. CAIX Inhibitor DTP348. NCI Thesaurus. Code C117731.

An orally bioavailable, nitroimidazole-based sulfamide, carbonic anhydrase IX (CAIX) inhibitor with potential antineoplastic activity. Upon administration, CAIX inhibitor DT P348 inhibits tumor-associated CAIX, a hypoxia-inducible transmembrane glycoprotein that catalyzes the reversible reaction and rapid interconversion of carbon dioxide and water to carbonic acid, protons, and bicarbonate ions. This prevents the acidification of the tumor's extracellular microenvironment and decreases the intracellular $\mathrm{pH}$. This results in increased cell death in CAIX-expressing, hypoxic tumors. In addition, DTP348, through its nitroimidazole moiety, is able to sensitize hypoxic tumor cells to irradiation. CAIX is overexpressed in various tumors and plays a key role in intra- and extracellular pH regulation, cancer cell progression, survival, migration and invasion. 